\title{
Relationship between Lingual Papilla Surface Roughness and Oral Condition in Elderly Individuals
}

\author{
Yoko Tada, Junichi Karaki, Junpei Kubota, Yasuaki Kakinoki \\ Department of Special Needs and Geriatric Dentistry, Kyushu Dental University, Kitakyushu, Japan \\ Email: r07sakakibara@fa.kyu-dent.ac.jp
}

How to cite this paper: Tada, Y., Karaki, J., Kubota, J. and Kakinoki, Y. (2021) Relationship between Lingual Papilla Surface Roughness and Oral Condition in Elderly Individuals. Open Journal of Stomatology, $11,77-90$

https://doi.org/10.4236/ojst.2021.112007

Received: December 28, 2020

Accepted: February 2, 2021

Published: February 5, 2021

Copyright $\odot 2021$ by author(s) and Scientific Research Publishing Inc. This work is licensed under the Creative Commons Attribution International License (CC BY 4.0).

http://creativecommons.org/licenses/by/4.0/

\begin{abstract}
Objectives: Recently, an increasing number of elderly patients have complained of tongue pain and fissured tongue, while atrophy of the lingual papillae with low nutrition has also become a commonly encountered condition. The viewpoint that lingual papilla atrophy reflects systemic and pathological conditions, such as diabetes and in the circulatory system abnormalities, is supported by many clinicians. The present study was conducted to clarify the relationship of degree of atrophy of tongue papillae with oral symptoms, with an aim to evaluate the usefulness of clinical diagnostic criteria for tongue papillae atrophy. Subjects and Methods: The subjects were asked to protrude the tongue forward. The tongue was held at rest and impressions were taken of the tongue dorsum $15 \mathrm{~mm}$ posterior to the apex of the tongue. Surface impressions were measured using a Surfcoder SE300 and the obtained values were used to define surface roughness (Ra). Multivariate analyses of the relationships between the Ra measurements and the living environment, subjective symptoms of oral health, and survey results of measurements were performed to examine factors associated with Ra. The tongue was photographed with a digital camera, then RGB color value of four random points $15 \mathrm{~mm}$ from the tongue apex was determined. Using those findings, redness was calculated. Results and Conclusions: One hundred and six subjects with a mean age of $79.5 \pm 9.2$ years were analyzed. In the smooth group, there was more redness in the tongue dorsum as compared to the rough group. Total and Sagittal Ra values of subjects with dysphagia were lower than those without dysphagia, suggesting that the degree of oral mucosal atrophy is related to subjective symptoms of dysphagia. Subjects with high water intake had higher Coronal Ra values, which was considered to be related to the edematous state of the lingual papillae.
\end{abstract}




\section{Keywords}

Lingual Papilla, Surface Roughness, Elderly, Color of Tongue Papillae, Atrophy

\section{Introduction}

Recently, an increasing number of elderly patients have complained of tongue pain, fissured tongue, geographic tongue, and smooth tongue, while atrophy of the lingual papillae with low nutrition has also become a commonly encountered condition [1] [2]. The viewpoint that lingual papilla atrophy reflects systemic and pathological conditions, such as diabetes [3], oral candidiasis [4], and Sjogren's syndrome [5] [7], as well as allergic tendencies and in the circulatory system abnormalities [6], is supported by many clinicians. In daily clinical practice, various tongue lesions are often seen in elderly patients and frequently accompanied by atrophy of the lingual papillae. Degree of lingual papilla atrophy degree was previously assessed by Negoro, et al. using a combination of video microscopy and contact endoscopy to observe the papillae [8], though such visual inspection is reliant on the observer's experience and subjective assessment. In another study, Amagasa determined surface roughness of the gingiva and mucosa of the alveolar ridge using an indirect measurement method [9], while Uemori et al. evaluated the degree of lingual papillae atrophy using surface roughness $(\mathrm{Ra})$ as a new assessment method and reported that it was significantly related to clinical assessment results [10].

The present study was conducted to clarify the relationship of degree of atrophy of tongue papillae with oral symptoms, with an aim to evaluate the usefulness of clinical diagnostic criteria for tongue papillae atrophy.

\section{Materials and Methods}

\subsection{Background}

The results of a survey of oral symptoms in elderly people living in nursing homes and silicon impressions of tongue mucosa obtained by Uemori et al. from March to October 2010 were analyzed. Consent forms for participation in this study were obtained from the subjects and stored at our department (Ethical Review of Kyushu Dental University, No. 10-003, 20-13).

\subsection{Methods}

1) Impression taking and impression surface measurement

The subject was seated in a chair and asked to protrude the tongue forward. The tongue was held at rest and impressions were taken of the mucosa on the dorsal surface $15 \mathrm{~mm}$ posterior to the apex of the tongue under no pressure. A plastic frame constructed by Uemori et al. was used for the impressions [10] along with a dental silicone rubber impression material (Genie; Morita, Inc.). 
Surface impressions were measured using a Surfcoder SE300 (Kosaka Research Institute, Inc., Tokyo) and the obtained values were used to define surface roughness $(\mathrm{Ra})$. Surface roughness $(\mathrm{Ra})$ refers to arithmetic mean roughness and the value is obtained by using average surface roughness as the reference line and averaging the distance from the reference line for the examined section.

In principle, we performed nine measurements in the sagittal plane and nine in the coronal plane of each sample, with the measurement position moved 1.0 $\mathrm{mm}$ for each. The average of seven sagittal plane measurements was defined as Sagittal $\mathrm{Ra}$, the average of seven coronal planes was defined as Coronal $\mathrm{Ra}$, and the average of the Sagittal and Coronal $\mathrm{Ra}$ was defined as Total Ra. Areas with significantly uneven impression surfaces were avoided. Measurement speed was $0.500 \mathrm{~mm} / \mathrm{s}$, measurement length was $5.00 \mathrm{~mm}$, and the depth cutoff value was $2.5 \mathrm{~mm}$, while the other settings were the same as the initial values.

Multivariate analyses of the relationships between the $\mathrm{Ra}$ measurements and the living environment, subjective symptoms of oral health, and survey results of measurements were performed to examine factors associated with Ra.

2) Clinical classification of papillary atrophy of the tongue

Using intraoral photographic data, three dentists performed a visual examination for determining a clinical diagnosis of lingual papilla atrophy. When a subject was not clinically classified as that by the three dentists, one other dentist performed the clinical diagnosis according to Uemori's diagnostic criteria [10]. The subjects were classified into three groups; Normal, Smooth, and Rough (Table 1). Those without intraoral photographic data were excluded from analysis.

3) RGB color value measurements using intraoral photography

The subject was asked to protrude their tongue forward and it was photographed with a digital camera (CASIO EXILIM EX-Z1200). A CASMATCH color chart (Funakoshi) used for image correction was copied onto the photograph and color tone levels were corrected with the ADOBE PHOTOSHOP CS5 EXTENDED image processing software, then RGB color value of four random points $15 \mathrm{~mm}$ from the tongue apex (Figure 1) was determined. Using those findings, redness was calculated using the following equation: $r=R /(R+G+B)$. Areas inside of the grooves were excluded because of their different coloration. Subjects who were unable to sit without movement or uncooperative during intraoral photography were excluded from analysis.

4) Resting saliva volume

Resting saliva volume was measured using the exhaled saliva method [11]. Since all subjects were residents of a long-term care facility, a five-minute measurement was used to determine saliva secretion, then they were dived into the

Table 1. Clinical classification of atrophy of tongue.

Normal group: similar to healthy controls

Smooth group: smoother than healthy controls

Rough group: rougher than healthy controls 


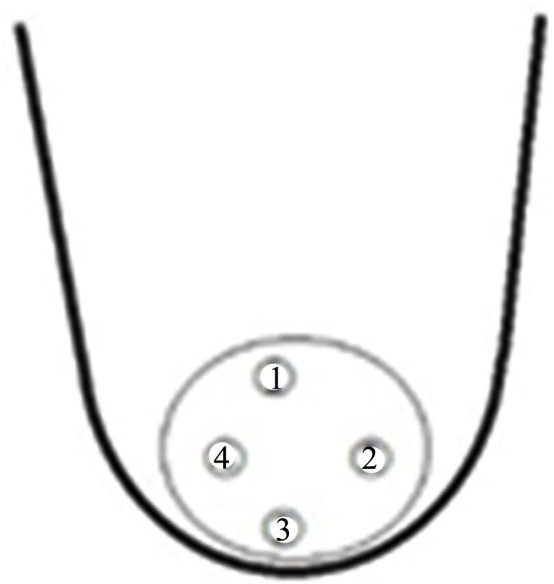

Figure 1. RGB measurement region, four points anterior from the tongue.

normal $(\geq 0.1 \mathrm{ml} / \mathrm{min})$ and low $(<0.1 \mathrm{ml} / \mathrm{min})$ flow group. Those that did not undergo these measurements were excluded from analysis.

5) Saliva wetness [12]

Saliva wetness test papers (KISO-Wet ${ }^{\circledR}$, KISO Science) were placed in contact with the tongue dorsum and the hypoglossal area, and the value for membrane suction in 10 seconds was recorded. Two sites were measured, the tongue dorsum $10 \mathrm{~mm}$ behind the apex and the hypoglossal area. Subjects with measured values for the tongue dorsum from $0-2.9 \mathrm{~mm}$ were considered to be in the dry group, from 3 - $4.9 \mathrm{~mm}$ were considered to be in the middle group, and $\geq 5 \mathrm{~mm}$ were considered to be in the high group, while subjects with measurements in the hypoglossal area from $0-4.9,5-9.9$, and $\geq 10 \mathrm{~mm}$ was considered to be in the dry, middle, and high group, respectively those that could not undergo these measurements were excluded from analysis.

6) Oral moisture meter value [13]

Oral mucosa moisture content was determined three times in each subject using an oral moisture meter (Moocas, Inc.), with the average used as the measured value. Two sites were measured, the tongue dorsum, $10 \mathrm{~mm}$ behind the apex, and the central part of the buccal mucosa, $30 \mathrm{~mm}$ behind the angle of the mouth. Subjects with measurements of $\leq 27.9$ were considered to be in the low oral fluid level group, 28.0 to 29.5 in the borderline oral fluid level group, and $\geq 29.6$ in the normal oral fluid level group. Those that could not undergo these measurements were excluded.

7) Salivary amylase

Saliva was collected by placing a saliva collection paper the hypoglossal area for 30 seconds, then the activity level of amylase was determined with a saliva amylase monitor (Nipro Corporation), originally developed as an enzyme analyzer [14] [15]. Salivary amylase monitor readings are considered to provide quantitative indication of stress changes in the body. Based on the results, the subjects divided into four groups, with $0-30 \mathrm{KU} / \mathrm{L}$ indicating no stress, $31-45$ $\mathrm{KU} / \mathrm{L}$ indicating mild stress, $46-60 \mathrm{KU} / \mathrm{L}$ indicating moderate stress, and 61 - 
$200 \mathrm{KU} / \mathrm{L}$ indicating severe stress [16]. Subject who were unable to undergo these measurements were excluded from analysis.

8) Subjective symptoms and living environment

For determining subjective symptoms and living environment, we interviewed the subjects or their family members, or other caregivers who met them on a daily basis and filled out a record sheet. Subjective symptoms were "dry mouth feeling" and "difficulty with swallowing", and the amount of fluid intake outside of meals was also recorded. Unmarked items were excluded from analysis.

Four arbitrary points $15 \mathrm{~mm}$ anterior from the tongue (numbers in circles) were used as measurement regions. Areas such as the inside of grooves of the tongue were excluded because of differences in color tone.

\section{Results}

\subsection{Subjects}

A total of 106 subjects were analyzed, including 31 males (29.2\%) and 75 females $(70.8 \%)$, with a mean age of $79.5 \pm 9.2$ years. Ages ranged from 61 to 99 years, with 22 (20.8\%) under 70, 35 (33.0\%) in their 70s, 36 (34.0\%) in their 80s, and 13 $(12.2 \%)$ in their 90 s (Table 2 ). Ra values by age and gender are shown in Table 3 and Table 4, respectively. There were no significant differences between age and Ra value (Spearman's rank correlation coefficient, $\mathrm{p}=0.8820$ ), or between gender and Ra value (Mann-Whitney U test, $\mathrm{p}=0.9941$ ).

Table 2. Subjects $(\mathrm{n}=106)$.

\begin{tabular}{cccc}
\hline Age (years) & Total no. & Male & Female \\
\hline $61-69$ & $22(20.8 \%)$ & $10(9.5 \%)$ & $12(11.3 \%)$ \\
$70-79$ & $35(33.0 \%)$ & $12(11.3 \%)$ & $23(21.7 \%)$ \\
$80-89$ & $36(34.0 \%)$ & $8(7.5 \%)$ & $28(26.5 \%)$ \\
$90-99$ & $13(12.2 \%)$ & $1(0.9 \%)$ & $12(11.3 \%)$
\end{tabular}

Table 3. Age and Ra value $(\mu \mathrm{m})(\mathrm{n}=106)$.

\begin{tabular}{ccccc}
\hline Age (years) & No. of subjects & Sagittal Ra & Coronal Ra & Total Ra \\
\hline $61-69$ & $22(20.8 \%)$ & $51.1 \pm 15.0$ & $61.6 \pm 18.2$ & $56.4 \pm 14.2$ \\
$70-79$ & $35(33.0 \%)$ & $51.3 \pm 18.3$ & $62.1 \pm 17.9$ & $56.7 \pm 17.0$ \\
$80-89$ & $36(34.0 \%)$ & $54.0 \pm 16.8$ & $64.1 \pm 16.8$ & $59.1 \pm 15.3$ \\
$90-99$ & $13(12.2 \%)$ & $51.7 \pm 17.1$ & $55.8 \pm 21.6$ & $53.8 \pm 18.0$ \\
\hline
\end{tabular}

Table 4. Gender and Ra value $(\mu \mathrm{m})(\mathrm{n}=106)$.

\begin{tabular}{cccccc}
\hline & No. of subjects & $\begin{array}{c}\text { Average age } \pm \text { standard } \\
\text { deviation (years) }\end{array}$ & Sagittal Ra & Coronal Ra & Total Ra \\
\hline Male & $31(29.2 \%)$ & $74.5 \pm 8.2$ & $52.0 \pm 18.3$ & $62.9 \pm 19.0$ & $57.5 \pm 17.3$ \\
Female & $75(70.8 \%)$ & $79.5 \pm 9.2$ & $52.3 \pm 16.3$ & $61.5 \pm 17.1$ & $56.9 \pm 15.4$ \\
\hline
\end{tabular}




\subsection{Ra Value}

Surface roughness of the impression surface was determined using a Surfcoder SE300. Three subjects who did not cooperate were excluded and 103 samples were measured. The Sagittal Ra value was $52.2 \pm 16.8 \mu \mathrm{m}$, the Coronal Ra value was $61.9 \pm 18.0 \mu \mathrm{m}$, and the Total $\mathrm{Ra}$ value was $57.0 \pm 15.9 \mu \mathrm{m}$ (Table 5). Spearman's rank correlation coefficient analysis showed that the correlation was significantly greater for Coronal $\mathrm{Ra}$, followed by Total $\mathrm{Ra}$ and Sagittal $\mathrm{Ra}$ ( $\mathrm{p}<$ $0.05, \mathrm{p}<0.01$, respectively) (Figure 2 ).

\subsection{Clinical Classification of Papillary Atrophy of the Tongue}

Using photographic data obtained for 96 subjects, the degree of lingual papilla atrophy was classified by visual examinations conducted by three dentists. There were 24 subjects $(25.0 \%)$ in the smooth group, 66 (68.8\%) in the normal group, and $6(6.2 \%)$ in the rough group. The probability of agreement between all three dentists' classifications was $53.1 \%$, while the probability of agreement between two dentists' classifications was $97.9 \%$.

When Spearman's rank correlation coefficient was used, there was a significant positive correlation between clinical classification of lingual papillary atrophy and Total Ra value ( $\mathrm{p}=0.0171)$, and between clinical classification of lingual papillary atrophy and Coronal Ra value $(\mathrm{p}=0.0040)$ (Figure 3, Figure 4). However, there was no correlation between clinical classification of lingual papillary atrophy and Sagittal Ra value (Figure 5).

Table 5. Ra value determined with surface roughness measuring instrument $(\mu \mathrm{m})(\mathrm{n}=$ 103).

\begin{tabular}{|c|c|c|}
\hline Sagittal Ra & $52.2 \pm 16.8$ & ᄀ \\
\hline Coronal Ra & $61.9 \pm 18.0$ & * \\
\hline Total Ra & $57.0 \pm 15.9$ & \\
\hline
\end{tabular}

${ }^{\star} \mathrm{p}<0.05,{ }^{* *} \mathrm{p}<0.01$ (Mann-Whitney's U test).

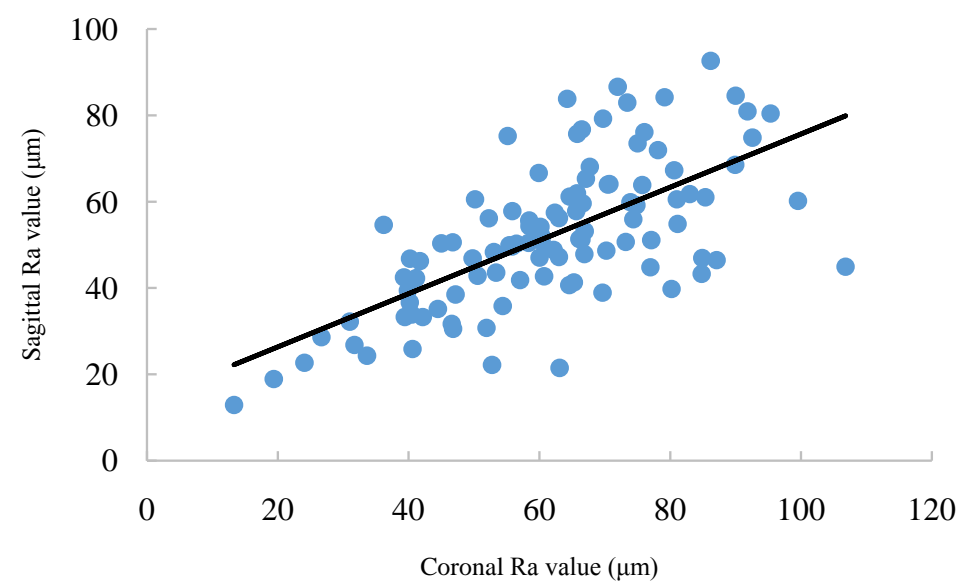

Figure 2. Relationship between Sagittal and Coronal Ra. Spearman's rank correlation coefficient, $\mathrm{p}<0.0001$ (correlations between groups were found) $(\mathrm{r}=0.656240)$. 


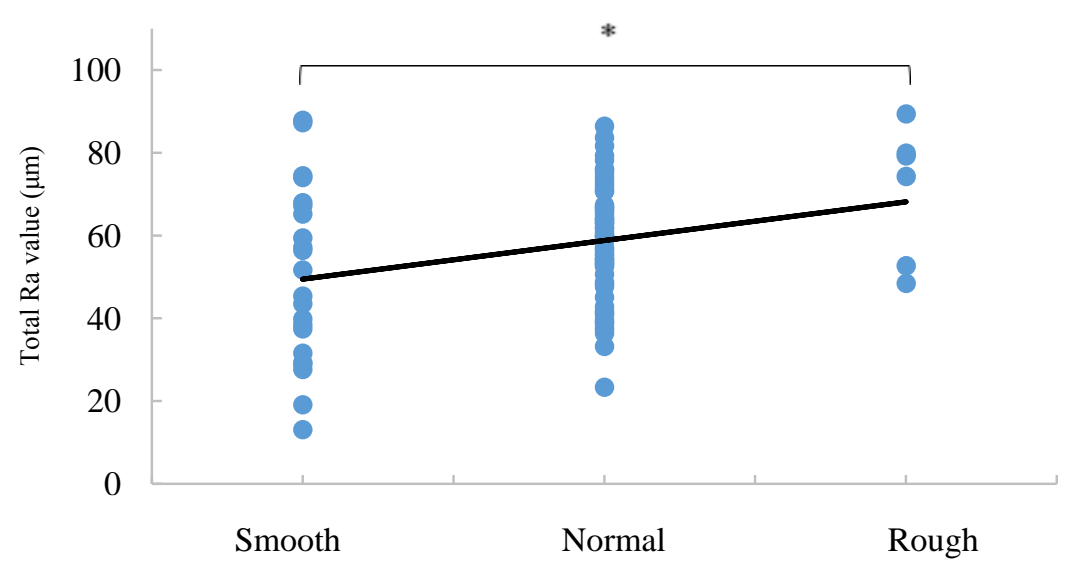

Figure 3. Total Ra value and clinical classification of atrophy of tongue. Spearman's rank correlation coefficient, $\mathrm{p}<0.0001$ (correlations between groups were found) $(\mathrm{r}=$ $0.656240)$.

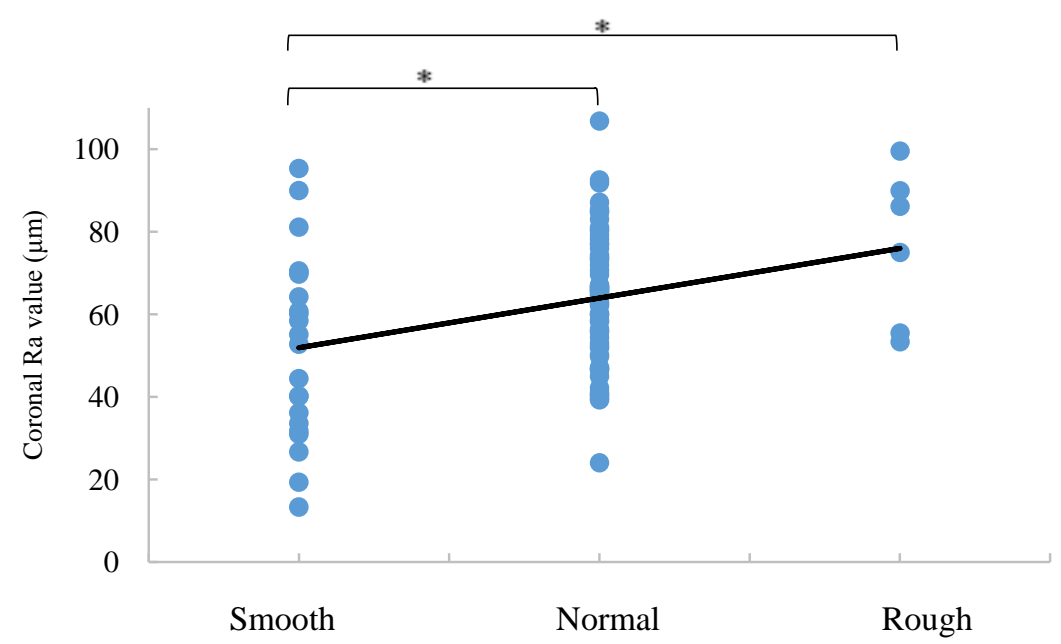

Figure 4. Coronal Ra value and clinical classification of atrophy of tongue. Spearman's rank correlation coefficient, $\mathrm{p}<0.0001$ (correlations between groups were found) $(\mathrm{r}=$ $0.656240)$.

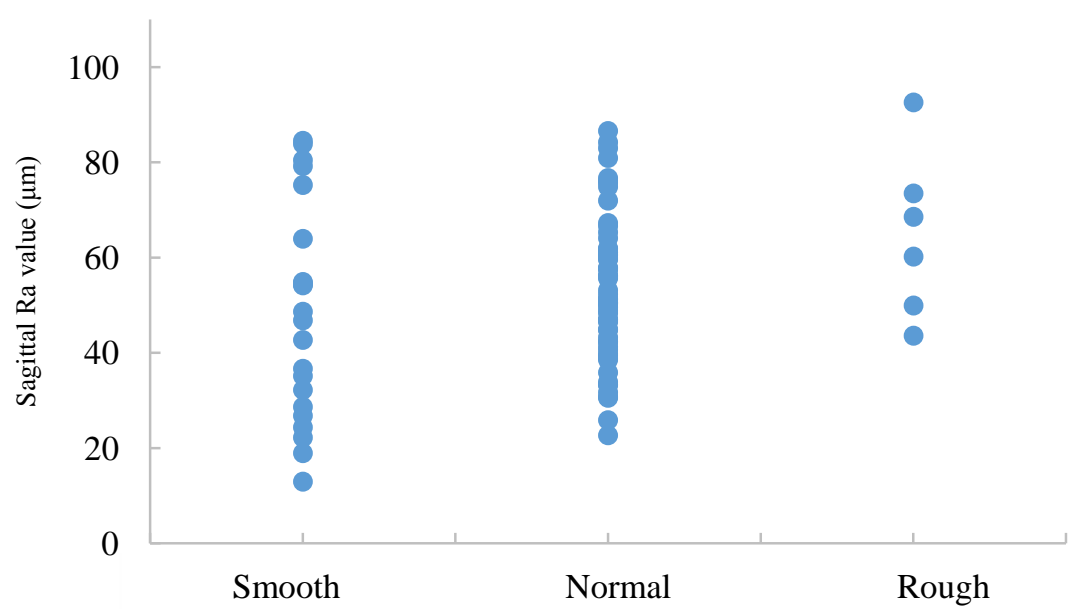

Figure 5. Sagittal Ra value and clinical classification of atrophy of tongue. Spearman's rank correlation coefficient, $\mathrm{p}=0.185240$. 
Ra values for the three groups are shown in Table 6. Coronal Ra values for the rough group were significantly $(\mathrm{p}<0.05)$ greater than those for the smooth group, while Coronal Ra values for the normal group were significantly ( $\mathrm{p}<$ 0.05) greater than those for the smooth group. Total $\mathrm{Ra}$ values for the rough group were also significantly $(\mathrm{p}<0.05)$ greater than the Total Ra value for the smooth group.

\subsection{Relationship with RGB Color Value}

RGB color values were determined using color-corrected photographs of the lingual apex of the tongue obtained from 96 subjects who were able to cooperate with the examination. Spearman's rank correlation coefficient testing revealed a negative correlation between redness and clinical classification of lingual papillary atrophy $(\mathrm{p}=0.0258)$. Redness in the smooth group was significantly $(\mathrm{p}<$ $0.05)$ greater than that in the normal group (Figure 6).

\subsection{Resting Saliva Volume}

Resting saliva volume of the oral mucosa was determined using a spitting technique. There were 48 patients $(45.5 \%)$ in the normal $(>0.1 \mathrm{ml} / \mathrm{min})$ and 53 patients $(52.5 \%)$ in the low flow $(\leq 0.1 \mathrm{ml} / \mathrm{min})$ group (Table 7$)$. The low flow

Table 6. Clinical classification and Ra value related to tongue atrophy $(\mu \mathrm{m})(\mathrm{n}=96)$.

$\left.\begin{array}{lllll}\hline & \text { No. of subjects } & \text { Sagittal Ra } & \text { Coronal Ra } & \text { Total Ra } \\ \text { Smooth group } & 24(25.0 \%) & 48.2 \pm 22.4 & 52.1 \pm 22.3 \\ \text { Normal group } & 66(68.8 \%) & 52.9 \pm 14.7 & 63.8 \pm 15.9\end{array}\right] * \begin{aligned} & 50.1 \pm 21.3 \\ & \text { Rough group }\end{aligned}$

${ }^{\star} \mathrm{p}<0.05$ (Mann-Whitney's U test).

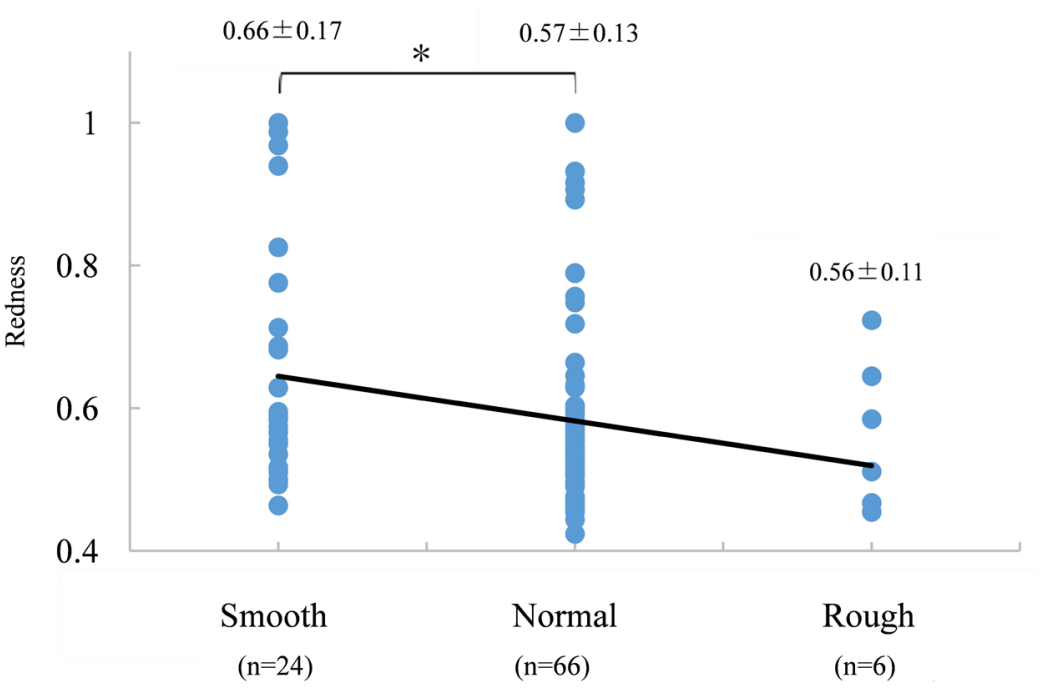

Figure 6. Clinical classification of redness and atrophy of tongue. Spearman's rank correlation coefficient, $\mathrm{p}=0.0258$ (correlations between groups were found) $(\mathrm{r}=-0.228773$ ). ${ }^{*} \mathrm{p}<0.05$ (Mann-Whitney's U test). 
Table 7. Resting saliva volume and Ra value $(\mu \mathrm{m})(\mathrm{n}=101)$.

\begin{tabular}{ccccc}
\hline & No. of subjects & Sagittal Ra & Coronal Ra & Total Ra \\
\hline Low flow group $(\leq 0.1 \mathrm{ml} / \mathrm{min})$ & $53(52.5 \%)$ & $51.0 \pm 17.3$ & $60.1 \pm 18.8$ & $55.6 \pm 16.9$ \\
Normal flow group $(>0.1 \mathrm{ml} / \mathrm{min})$ & $48(45.5 \%)$ & $54.2 \pm 17.3$ & $63.8 \pm 17.5$ & $59.0 \pm 14.9$ \\
\hline${ }^{*}<0.05$ (Mann-Whitney's U test). & & & &
\end{tabular}

group subjects had lower Ra values than those in the normal flow group, though the difference was not statistically significant.

\subsection{Saliva Wetness}

The mean value for the tongue dorsum in the 10 -second saliva wetness test was $2.9 \pm 2.6 \mathrm{~mm}$ and 58 (56.3\%) subjects in the low group had a value lower than 3 $\mathrm{mm}$ (Table 8). There was no significant difference for Ra values in relation to saliva wetness on the tongue dorsum. The mean value for the hypoglossal area was $5.0 \pm 5.2 \mathrm{~mm}$ and $66(64.1 \%)$ in the low group had a hypoglossal measurement of less than $5 \mathrm{~mm}$ (Table 9).

In the group with low hypoglossal saliva wetness, the Sagittal Ra value was $53.8 \pm 18.1 \mu \mathrm{m}$, Coronal $\mathrm{Ra}$ value was $64.0 \pm 19.4 \mu \mathrm{m}$, and Total Ra value was $58.9 \pm 17.3 \mu \mathrm{m}$, while those values in the middle group were $53.2 \pm 11.0 \mu \mathrm{m}, 58.2$ $\pm 15.4 \mu \mathrm{m}$, and $55.7 \pm 13.9 \mu \mathrm{m}$, respectively, and in the high group were $48.5 \pm$ $14.9 \mu \mathrm{m}, 57.8 \pm 15.6 \mu \mathrm{m}$, and $55.7 \pm 13.9 \mu \mathrm{m}$, respectively. In the middle group, the Total Ra value was larger than Sagittal $\mathrm{Ra}(53.2 \pm 11.0 \mu \mathrm{m})$ and Coronal Ra $(58.2 \pm 15.4 \mu \mathrm{m})$, as well as compared to Sagittal Ra $(48.5 \pm 14.9 \mu \mathrm{m})$, Coronal $\mathrm{Ra}(57.8 \pm 15.6 \mu \mathrm{m})$, and Total $\mathrm{Ra}(53.1 \pm 13.6 \mu \mathrm{m})$ in the high group, though the differences were not statistically significant.

\subsection{Oral Moisture Levels}

The mean value for oral fluid measurement in the tongue dorsum was $27.8 \pm 4.3$, with 47 (45.6\%) subjects showing a value of $\leq 27.9$ (Table 10). In the group with low moisture on the tongue dorsum, the Ra value was higher as compared to the borderline and normal groups, though the differences were not statistically significant.

The average oral fluid level in the buccal mucosa was $28.9 \pm 2.7$, with 32 (31.1\%) of the subjects showing a level $\leq 27.9$ (Table 11). There were no significant differences for Ra values in the buccal mucosa among the subjects.

\subsection{Salivary Amylase}

Salivary amylase monitor values are shown in Table 12 . There were 44 patients $(46.3 \%)$ in the severe stress group, with a salivary amylase level $\geq 61 \mathrm{KU} / \mathrm{L}$.

\subsection{Subjective Symptoms and Living Environment}

Fifty respondents (47.6\%) reported experiencing subjective symptoms related to oral sensation either "always" or "sometimes" for dry mouth, and 19 (18.1\%) 
Table 8. Saliva wetness of the tongue dorsum and Ra value $(\mu \mathrm{m})(\mathrm{n}=103)$.

\begin{tabular}{ccccc}
\hline & No. of subjects & Sagittal Ra & Coronal Ra & Total Ra \\
\hline Low group $(0-2.9 \mathrm{~mm})$ & $58(56.3 \%)$ & $51.9 \pm 17.4$ & $61.8 \pm 20.2$ & $56.9 \pm 17.0$ \\
Middle group $(3-5 \mathrm{~mm})$ & $28(27.2 \%)$ & $53.4 \pm 15.8$ & $61.4 \pm 11.4$ & $57.4 \pm 12.4$ \\
High group $(>5 \mathrm{~mm})$ & $17(16.5 \%)$ & $53.1 \pm 16.9$ & $62.8 \pm 21.0$ & $57.9 \pm 18.3$ \\
\hline
\end{tabular}

Table 9. Salivary wetness of the hypoglossal area and Ra value $(\mu \mathrm{m})(\mathrm{n}=103)$.

\begin{tabular}{ccccc}
\hline & No. of subjects & Sagittal Ra & Coronal Ra & Total Ra \\
\hline Low group $(0-4.9 \mathrm{~mm})$ & $66(64.1 \%)$ & $53.8 \pm 18.1$ & $64.0 \pm 19.4$ & $58.9 \pm 17.3$ \\
Middle group $(5-10 \mathrm{~mm})$ & $13(12.6 \%)$ & $53.2 \pm 11.0$ & $58.2 \pm 15.4$ & $55.7 \pm 11.9$ \\
High group $(>10 \mathrm{~mm})$ & $24(23.3 \%)$ & $48.5 \pm 14.9$ & $57.8 \pm 15.6$ & $53.1 \pm 13.6$ \\
\hline
\end{tabular}

Table 10. Oral moisture levels of the tongue dorsum and Ra value $(\mu \mathrm{m})(\mathrm{n}=103)$.

\begin{tabular}{ccccc}
\hline & No. of subjects & Sagittal Ra & Coronal Ra & Total Ra \\
\hline Low group $(\leq 27.9)$ & $47(45.6 \%)$ & $53.2 \pm 15.8$ & $64.0 \pm 18.1$ & $58.6 \pm 15.1$ \\
Borderline group $(28.0-29.5)$ & $21(20.4 \%)$ & $52.5 \pm 15.6$ & $63.6 \pm 13.2$ & $58.1 \pm 12.8$ \\
Normal group $(>29.5)$ & $35(34.0 \%)$ & $51.6 \pm 19.0$ & $57.7 \pm 20.6$ & $54.6 \pm 18.9$ \\
\hline
\end{tabular}

Table 11. Oral moisture levels in buccal mucosa and Ra values $(\mu \mathrm{m})(\mathrm{n}=103)$.

\begin{tabular}{ccccc}
\hline & No. of subjects & Sagittal Ra & Coronal Ra & Total Ra \\
\hline Low group $(\leq 27.9)$ & $32(31.1 \%)$ & $52.4 \pm 18.5$ & $62.2 \pm 18.0$ & $57.3 \pm 16.7$ \\
Borderline group $(28.0-29.5)$ & $24(23.3 \%)$ & $52.7 \pm 14.0$ & $66.2 \pm 18.4$ & $59.5 \pm 14.1$ \\
Normal group $(>29.5)$ & $47(45.6 \%)$ & $52.5 \pm 17.2$ & $59.3 \pm 18.2$ & $55.9 \pm 16.6$ \\
\hline
\end{tabular}

Table 12. Salivary amylase monitor values and Ra value $(\mu \mathrm{m})(\mathrm{n}=95)$.

\begin{tabular}{ccccc}
\hline Base value (KU/L) & No. of subjects & Sagittal Ra & Coronal Ra & Total Ra \\
\hline No stress group $(0-30)$ & $34(35.8 \%)$ & $49.4 \pm 16.2$ & $60.3 \pm 18.1$ & $54.8 \pm 15.6$ \\
Mild stress group $(31-45)$ & $12(12.6 \%)$ & $54.9 \pm 19.7$ & $58.9 \pm 19.4$ & $56.9 \pm 19.2$ \\
Moderate stress group $(46-60)$ & $5(5.3 \%)$ & $52.1 \pm 16.1$ & $58.6 \pm 12.8$ & $55.3 \pm 14.5$ \\
Severe stress group (61-200) & $44(46.3 \%)$ & $54.2 \pm 16.2$ & $65.7 \pm 18.6$ & $60.0 \pm 15.5$ \\
\hline
\end{tabular}

reporting dysphagia (Table 13, Table 14). The Total Ra values for "always" and "sometimes" were significantly $(\mathrm{p}<0.05)$ lower than the Total Ra values for "not much" and "never" in terms of dysphagia. Additionally, the Sagittal Ra values for "always" and "sometimes" were significantly $(\mathrm{p}<0.05)$ lower than the Sagittal Ra values for "not much" and "never".

Subjects who noted awareness of dysphagia "always" or "sometimes" were also significantly $(\mathrm{p}<0.05)$ more likely to report xerostomia. The value in the resting saliva for those who "always" or "sometimes" experienced dysphagia was $0.07 \pm 0.1 \mathrm{ml} / \mathrm{min}$, which was significantly $(\mathrm{p}<0.05)$ lower than that $(0.17 \pm 0.2$ $\mathrm{ml} / \mathrm{min}$ ) of those who noted dysphagia "not much" or "never". 
The value for oral moisture levels in the tongue dorsum for subjects who noted dysphagia "not much" or "never" was $29.6 \pm 2.0$, which was significantly $(\mathrm{p}<0.05)$ higher than that $(27.4 \pm 4.5)$ for subjects who reported awareness of dysphagia "always" or "sometimes" (Table 15). The Coronal Ra value was positively correlated with daily fluid intake $(\mathrm{p}=0.0203)$ (Figure 7).

Table 13. Subjective symptoms of oral dryness and Ra values $(\mu \mathrm{m})(\mathrm{n}=105)$.

\begin{tabular}{ccccc}
\hline & No. of subjects & Sagittal Ra & Coronal Ra & Total Ra \\
\hline Always/Sometimes & $50(47.6 \%)$ & $52.4 \pm 17.8$ & $61.9 \pm 20.2$ & $57.1 \pm 17.6$ \\
Not much/never & $55(52.4 \%)$ & $51.9 \pm 16.2$ & $61.7 \pm 16.0$ & $56.8 \pm 14.3$ \\
\hline
\end{tabular}

Table 14. Subjective symptoms of dysphagia and Ra values $(\mu \mathrm{m})(\mathrm{n}=105)$.

$\left.\left.\begin{array}{ccccc}\hline & \text { No. of subjects } & \text { Sagittal Ra } & \text { Coronal Ra } & \text { Total Ra } \\ \text { Always/sometimes } & 19(18.1 \%) & 44.8 \pm 15.5 & 55.9 \pm 18.1 \\ \hline \text { Not much/never } & 86(81.9 \%) & 53.7 \pm 16.8 & 63.2 \pm 17.9\end{array}\right] * \begin{array}{c}50.3 \pm 15.4 \\ 58.4 \pm 15.7\end{array}\right] *$

${ }^{\star} \mathrm{p}<0.05$ (Mann-Whitney's U test).

Table 15. Subjective symptoms of dysphagia and other associations.

\begin{tabular}{|c|c|c|c|c|c|c|c|c|}
\hline \multirow[t]{2}{*}{$\begin{array}{l}\text { Subjective symptoms } \\
\text { of dysphagia }\end{array}$} & \multicolumn{4}{|c|}{$\begin{array}{l}\text { Subjective symptoms of dry } \\
\text { mouth }\end{array}$} & \multirow{2}{*}{\multicolumn{2}{|c|}{$\begin{array}{l}\text { Resting saliva volume } \\
(\mathrm{ml} / \mathrm{min})\end{array}$}} & \multirow{2}{*}{\multicolumn{2}{|c|}{$\begin{array}{l}\text { Oral moisture levels } \\
\text { of the tongue dorsum }\end{array}$}} \\
\hline & 1 & 23 & 4 & & & & & \\
\hline Always/sometimes & & $\begin{array}{c}5 \\
(n=19)\end{array}$ & 2 & キ & $\begin{array}{c}0.07 \pm 0.1 \\
(\mathrm{n}=17)\end{array}$ & $*$ & $\begin{array}{c}29.6 \pm 2.0 \\
(\mathrm{n}=17)\end{array}$ & * \\
\hline Not much/never & 15 & $\begin{array}{l}20 \quad 22 \\
(\mathrm{n}=85)\end{array}$ & & & $\begin{array}{c}0.17 \pm 0.2 \\
(\mathrm{n}=83)\end{array}$ & & $\begin{array}{c}27.4 \pm 4.5 \\
(\mathrm{n}=85)\end{array}$ & \\
\hline
\end{tabular}

${ }^{*} \mathrm{p}<0.05$ (Mann-Whitney's U test), † p $<0.05$ (chi-squared test). Symptoms: 1 , always; 2 , sometimes; 3 , not much; 4 , never.

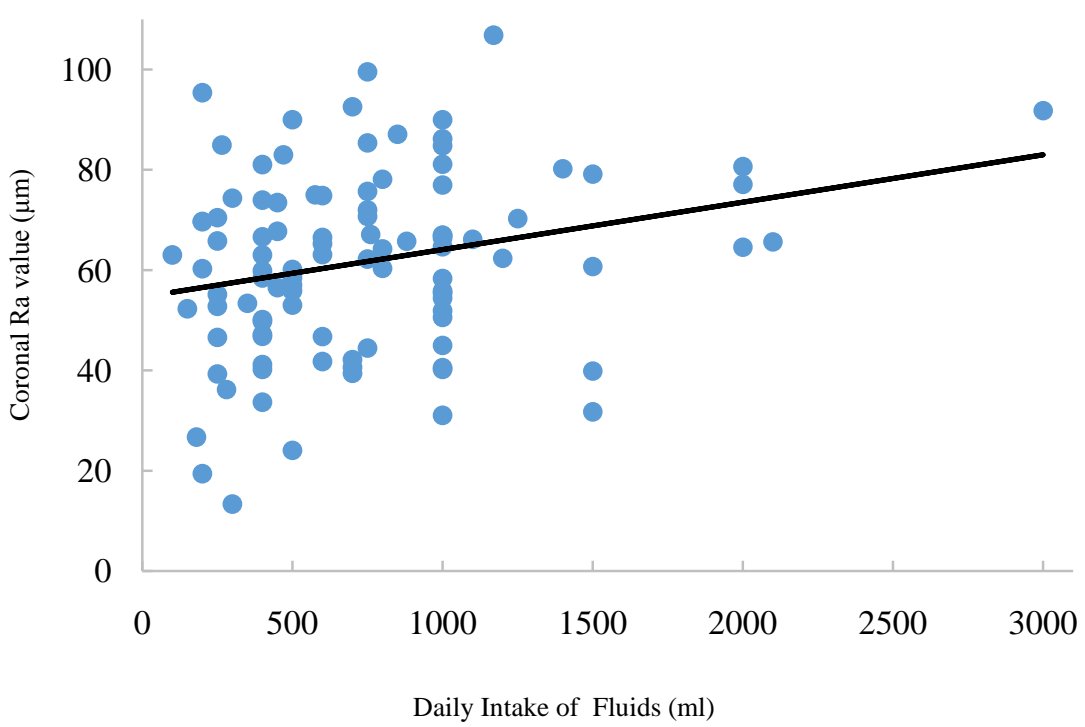

Figure 7. Coronal Ra values and daily intake of fluids other than food. Spearman's rank correlation coefficient, $\mathrm{p}=0.0203$ (correlations between groups were found) $(\mathrm{r}=0.23300)$. 


\section{Discussion}

For objective evaluation of lingual papilla atrophy, Uemori et al. developed a method for evaluating surface roughness ( $\mathrm{Ra}$ ) by use of a dedicated instrument and reported results that were significantly related to clinical evaluations [10]. In this study, surface roughness was determined using a Surfcoder SE300, a different instrument than the one used by Uemori. Using those measurements, the relationships of subjective symptoms related to xerostomia with resting saliva volume, saliva wetness value, oral moisture levels, salivary amylase monitor values, and RGB color values were examined. The subjects were elderly individuals who were living in care facilities, of whom $70.8 \%$ were female and $67.0 \%$ were aged from 70 - 89 years.

Total and Coronal Ra values were found to be correlated with the clinical classification of lingual papilla atrophy, and Ra values measured using the present instrument were also considered useful for clinical evaluations. The Ra values were largest for Coronal Ra, following by Total Ra and then Sagittal Ra. This is because the grooves of a fissured tongue often run in a sagittal direction, making it possible to avoid them when determining Sagittal Ra in a clinical setting, while the unevenness of the grooves cannot be avoided and are included as a measure of surface roughness when determining Coronal $\mathrm{Ra}$, thus it was largest in the present study.

The three dentists who performed clinical classifications of papillary lingual atrophy by visual examinations were skilled and each had more than five years of clinical experience, thus agreement among them was considered to be high. For the clinical classification of lingual papillary atrophy, there was a positive correlation between Total and Coronal Ra values, while there was none with Sagittal Ra values. Therefore, we concluded that it is clinically useful to determine the Ra value in the coronal plane direction, even if the grooves of a fissured tongue are included during the measurement.

Redness was higher in the smooth group and lower in the rough group as compared to the normal group. The value for the rough group was lower than that for the smooth group because of increased tongue mucosa keratinization, which gave it a whiter appearance. The smooth group reflected the color tone of capillaries on the tongue surface, and was thought to be related to systemic conditions such as dehydration. It was significantly $(\mathrm{p}<0.05)$ greater as compared to the normal group, but not significantly different from the rough group, likely due to the small number of subjects in the latter 6 .

There was no association of Ra values for resting saliva volume, saliva wetness, or oral moisture levels. There was also no correlation between salivary amylase measurements and Ra values, suggesting that the degree of lingual papilla atrophy at the tongue apex may be less affected by stress.

Regarding dysphagia, the Total Ra value for subjects who always or sometimes experienced dysphagia was lower than that of those who rarely or never experienced dysphagia, suggesting a lingual papilla atrophy tendency. Similarly, the Sagittal Ra value of subjects who "always" or "sometimes" experienced dyspha- 
gia was lower than that those who "not much" or "never" experienced that condition, again suggesting a tendency for lingual papilla atrophy.

Subjects who had swallowing difficulty also had a stronger sense of xerostomia. Values obtained with the spit method were low, thus it was considered that those objective findings indicated a dry oral condition and difficulty with swallowing due to dryness. Subjects with swallowing difficulty found it difficult to hold saliva on the surface of the oral mucosa, partly due to lingual papillae atrophy. In addition, those subjects had higher oral moisture meter value on the tongue dorsum, suggesting difficulty with swallowing saliva and that those higher values might be due to saliva accumulation on the tongue.

There was a positive correlation between Coronal Ra value and daily fluid intake. Based on this finding we considered that edema of the papillae of the tongue might have occurred and the Ra value may be greater in individuals with a high level of water intake.

\section{Conclusions}

When the degree of lingual papilla atrophy was determined using Ra values, there was a correlation between clinical diagnosis of lingual papilla atrophy based on visual examination findings, and Total and Sagittal Ra values. Thus, measurements of Total and Sagittal Ra may be an effective diagnostic method that does not rely on clinical experience or visual examination, allowing for objective recording of changes over time.

In the smooth group, there was more redness in the tongue dorsum as compared to the rough group. Total and Sagittal Ra values of subjects with dysphagia were lower than those without dysphagia, suggesting that the degree of oral mucosal atrophy is related to subjective symptoms of dysphagia. Subjects with dysphagia also had lower spit measurement values as compared to those without dysphagia, suggesting a dry oral cavity. On the other hand, those with dysphagia had higher oral moisture meter value on the tongue dorsum than subjects without dysphagia, suggesting that saliva accumulation on the tongue dorsum was caused by difficulty with swallowing. Finally, subjects with high water intake had higher Coronal Ra values, which was considered to be related to the edematous state of the lingual papillae.

\section{Acknowledgements}

We thank the nursing home staff as well as Dr. Shinichi Hattori and other members of the Saga Dental Association for their support with this study.

\section{Conflicts of Interest}

The authors have no conflicts of interest to declare in regard to this article.

\section{References}

[1] Drinka, P.J., Langer, E.H., Voeks, S.K., Scott, L. and Morrow, F.D. (1993) Nutritional Correlates of Atrophic Glossitis: Possible Role of Vitamin E in Papillary Atrophy. 
Journal of the American College of Nutrition, 12, 14-20. https://doi.org/10.1080/07315724.1993.10718276

[2] Bøhmer, T. and Mowé, M. (2000) Tongue Atrophy-A Marker of Malnutrition. Tidsskr nor Laegeforen, 120, 900-903.

[3] Kawaguchi, H. (1996) The Fungi form Papillae of The Tongue and The Electric Gustatory Threshold in Diabetics. Practica Oto-Rhino-Laryngologica (Kyoto), 89, 249-262.

[4] Terai, H. and Shimahara, M. (2005) Atrophic Tongue Associated with Candida. Journal of Oral Pathology \& Medicine, 34, 397-400. https://doi.org/10.1111/j.1600-0714.2005.00324.x

[5] Maeda, M. (2006) Dermoscopic Patterns of The Filiform Papillae of The Tongue in Patients with Sjögren's Syndrome. The Journal of Dermatology, 33, 96-102. https://doi.org/10.1111/j.1346-8138.2006.00020.x

[6] Järvinen, J. and Kotilainen, A.-M.R. (1989) Some Local and Systemic Factors Related to Tongue Inflammation. Proceedings of the Finnish Dental Society, 85, 199-209.

[7] Yamamoto, K., Kurihara, M., Matsusue, Y., Komatsu, Y., Tsuyuki, M., Fujimoto, T., Nakamura, S. and Kirita, T. (2009) Atrophic Change of Tongue Papilla in $44 \mathrm{~Pa}$ tients with Sjögren Syndrome. Oral Surgery, Oral Medicine, Oral Pathology, Oral Radiology, and Endodontology, 107, 801-805.

https://doi.org/10.1016/j.tripleo.2009.02.018

[8] Negoro, A., Umemoto, M., Fukazawa, K., Terada, T. and Sakagami, M. (2004) Observation of Tongue Papillae by Video Microscopy and Contact Endoscopy to Investigate Their Correlation with Taste Function. Auris Nasus Larynx, 31, 255-259. https://doi.org/10.1016/j.anl.2004.01.009

[9] Amagasa, T. (1973) A Study on Surface Roughness of the Normal and Pathologic Gingiva. Journal of the Physical Society of Japan, 40, 428-456. https://doi.org/10.5357/koubyou.40.428

[10] Uemori, N., Kakinoki, Y., Karaki, J. and Kakigawa, H. (2012) New Method for Determining Surface Roughness of Tongue. Gerodontology, 29, 90-95. https://doi.org/10.1111/j.1741-2358.2011.00509.x

[11] Hino, T. and Okamoto, Y. (1997) Examination of Oropharyngeal Disease.1st Edition, Kanehara Publish, Tokyo, 3-14.

[12] Kakinoki, Y., Nisihara, T., Arita, M., Shibuya, K. and Ishikawa, M. (2004) Usefulness of New Wetness Tester for Diagnosis of Dry Mouth in Disabled Patients. Gerodontology, 21, 229-231. https://doi.org/10.1111/j.1741-2358.2004.00037.x

[13] Satoh-Kuriwada, S., Sasano, T., Furuuchi, T., Iikubo, M., Sugawara, Y. and Shoji, N. (2005) Clinical Evaluation of Oral Mucosal Moisture in Patients who Complained of Dry Mouth-Relation to the Whole Salivary Flow Rate. Journal of Japanese Society for Oral Mucous Membrane, 11, 8-15.

[14] Yamaguchi, M., Sakakima, J., Sato, K. and Nakano, K. (2007) Evaluation of the Sedative Effect of Fragrance on Filipinas Using a Biochemical Marker. Journal of Physiological Anthropology, 26, 247-251. https://doi.org/10.2114/jpa2.26.247

[15] Takai, N., Yamaguchi, M., Aragaki, T., Eto, K., Uchihashi, K. and Nishikawa, Y. (2007) Gender-Specific Differences in Salivary Biomarker Responses to Acute Psychological Stress. Annals of the New York Academy of Sciences, 1098, 510-515. https://doi.org/10.1196/annals.1384.014

[16] Morita, K., Kimura, H., Tsuka, H., Nishio, F., Yoshida, M. and Tsuga, K. (2020) Association between Salivary Alpha-Amylase and Subjective and Objective Oral Parafunctions in Community-Dwelling Elderly Individuals. Journal of Dental Sciences, 15, 310-314. https://doi.org/10.1016/j.jds.2020.05.004 